\title{
PENGARUH SISTEM OLAH TANAH DAN PEMUPUKAN NITROGEN JANGKA PANJANG TERHADAP EFISIENSI SERAPAN NITROGEN PADA TANAMAN PADI GOGO (Oryza sativa L.) TAHUN KE-27 DI LAHAN POLITEKNIK NEGERI LAMPUNG
}

\author{
Fajri Taufik Akbar, Muhajir Utomo \& Sarno \\ Jurusan Agroteknologi Fakultas Pertanian Universitas Lampung \\ J1. Prof. Dr. Soemantri Brodjonegoro, No. 1 Bandar Lampung 35145 \\ Email: fajritaufikakbar@yahoo.com
}

\begin{abstract}
ABSTRAK
Padi gogo merupakan tanaman pangan yang dibudidayakan di lahan kering. Salah satu upaya untuk meningkatkan efisiensi serapan nitrogen di lahan kering adalah dengan sistem olah tanah dan pemupukan nitrogen. Tujuan penelitian untuk mengetahui pengaruh sistem olah tanah dan pemupukan nitrogen jangka panjang terhadap efisiensi serapan nirogen pada tanaman padi gogo. Penelitian dilakukan di lahan Politeknik Negeri Lampung, dari bulan Oktober 2014 sampai dengan Maret 2015. Penelitian dilakukan dengan menggunakan Rancangan Acak Kelompok (RAK) yang disusun secara faktorial dengan 4 ulangan. Faktor pertama adalah sistem olah tanah jangka panjang yaitu $\mathrm{T}_{1}=$ Olah Tanah Intensif $(\mathrm{OTI}), \mathrm{T}_{2}=$ Olah Tanah Minimum $(\mathrm{OTM}), \mathrm{T}_{3}$ = Tanpa Olah Tanah (TOT), dan faktor kedua adalah pemupukan nitrogen jangka panjang yaitu $\mathrm{N}_{\mathrm{o}}=0 \mathrm{~kg} \mathrm{~N} \mathrm{ha}^{-1}, \mathrm{~N}_{1}=50 \mathrm{~kg} \mathrm{~N}$ ha $^{-1}$, dan $\mathrm{N}_{2}=100 \mathrm{~kg} \mathrm{~N} \mathrm{ha}^{-1}$. Analisis tanah dan tanaman dilakukan di Laboratorium Ilmu Tanah Jurusan Agroteknologi dan Laboratoium Pengelolaan Limbah Agroindustri Jurusan Teknologi Hasil Pertanian, Fakultas Pertanian, Universitas Lampung, Bandar Lampung. Data yang diperoleh diuji homogenitasnya dengan uji Barlet dan adifitasnya dengan uji Tukey serta diolah dengan analisis ragam dan dilanjutkan dengan uji Beda Nyata Jujur (BNJ) pada taraf 5\%. Hasil penelitian menunjukkan bahwa efisiensi serapan nitrogen antara sistem olah tanah OTM, TOT, dan OTI tidak berbeda nyata, dengan rerata mencapai 20,42\%, $22,15 \%$, dan 27,26\%; efisiensi serapan nitrogen antara pemupukan nitrogen dosis $50 \mathrm{~kg} \mathrm{~N}^{-1}{ }^{-1}$ dan $100 \mathrm{~kg} \mathrm{~N}^{-1}$ tidak berbeda nyata, dengan rerata mencapai $20,07 \%$ dan $26,49 \%$; dan tidak terdapat pengaruh interaksi antara sistem olah tanah dan pemupukan nitrogen jangka panjang terhadap efisiensi serapan nitrogen.
\end{abstract}

Kata kunci: efisiensi serapan nitrogen, padi gogo, pemupukan nitrogen, sistem olah tanah.

\section{PENDAHULUAN}

Padi termasuk bahan pangan yang dibutuhkan lebih dari separuh penduduk dunia. Kebutuhan padi sebagai salah satu sumber pangan utama terus meningkat, karena selain penduduk terus bertambah dengan laju peningkatan sekitar $2 \%$ per tahun, juga adanya perubahan pola konsumsi dari non beras ke beras. Pada sisi lain terjadinya penciutan lahan akibat konversi lahan untuk kepentingan non pertanian, dan munculnya fenomena degradasi kesuburan menyebabkan produktivitas padi cenderung melandai (Toha, 2005).

Salah satu upaya yang dilakukan untuk meningkatkan produktivitas padi pada lahan kering adalah dengan menggunakan prinsip olah tanah konservasi (OTK). Olah tanah konservasi merupakan cara penyiapan lahan yang dapat mengurangi mineralisasi bahan organik, erosi, dan penguapan dibandingkan dengan cara-cara penyiapan lahan konvensional (Abdurachman dkk., 1998). Selain dengan sistem olah tanah konservasi (OTK), usaha untuk meningkatkan produksi tanaman pangan juga dapat dilakukan dengan pemupukan. Pemupukan nitrogen diperlukan untuk pertumbuhan tanaman karena dapat menstimulir bagian-bagian vegetatif tanaman, seperti daun, batang, dan akar (Sutedjo, 2002) serta memperbesar butir-butir pada tanaman serealia (Brady dan Weil, 2008). Oleh sebab itu penyiapan lahan dengan sistem OTK dan pemupukan nitrogen merupakan upaya yang tepat untuk meningkatkan serapan hara dan hasil tanaman. Hal ini dapat terjadi karena kelembaban tanah yang tinggi pada sistem OTK dapat memacu serapan pupuk $\mathrm{N}$, sehingga efisiensi pemupukan $\mathrm{N}$ meningkat (Utomo, 2012).

Penelitian ini bertujuan untuk mengetahui pengaruh sistem olah tanah jangka panjang terhadap efisiensi serapan nitrogen pada tanaman padi gogo; Mengetahui pengaruh pemupukan nitrogen jangka panjang terhadap efisiensi serapan nitrogen pada tanaman padi gogo; dan Mengetahui pengaruh interaksi 
antara sistem olah tanah dan pemupukan nitrogen jangka panjang terhadap efisiensi serapan nitrogen pada tanaman padi gogo.

\section{BAHAN DAN METODE}

Penelitian yang merupakan penelitian jangka panjang tahun ke-27 ini dilakukan di lahan Politeknik Negeri Lampung yang berada pada $105^{\circ} 13^{\prime} 45,5^{\prime \prime}$ $105^{\circ} 13^{\prime} 48,0^{\prime \prime}$ BT dan $05^{\circ} 21^{\prime} 19,6^{\prime \prime}-05^{\circ} 21^{\prime} 19,7^{\prime \prime} \mathrm{LS}$, dengan elevasi $122 \mathrm{~m}$ dari permukaan laut (Utomo, 2012). Penelitian ini dilaksanakan pada bulan Oktober 2014 sampai dengan Maret 2015. Alat-alat yang digunakan dalam penelitian ini adalah cangkul, koret, bor tanah, timbangan, tali plastik, alat tulis, alat untuk kebutuhan analisa di laboratorium, dan alat-alat lain yang mendukung penelitian. Bahan-bahan yang digunakan pada penelitian ini adalah benih padi gogo varietas Inpago 8, herbisida Roundup dan Lindomin, pupuk Urea, SP-36, dan $\mathrm{KCl}$, dan bahan-bahan lain yang mendukung penelitian.

Penelitian dilakukan dengan menggunakan Rancangan Acak Kelompok (RAK) yang disusun secara faktorial dengan 4 ulangan. Faktor pertama adalah sistem olah tanah jangka panjang yaitu $\mathrm{T}_{1}=$ Olah Tanah Intensif (OTI), $\mathrm{T}_{2}=$ Olah Tanah Minimum (OTM), $\mathrm{T}_{3}$ = Tanpa Olah Tanah (TOT), dan faktor kedua adalah pemupukan nitrogen jangka panjang yaitu $\mathrm{N}_{\mathrm{o}}=0 \mathrm{~kg} \mathrm{~N}$ ha $^{-1}, \mathrm{~N}_{1}=50 \mathrm{~kg} \mathrm{~N} \mathrm{ha}^{-1}$, dan $\mathrm{N}_{2}=100 \mathrm{~kg} \mathrm{~N} \mathrm{ha}^{-1}$.

Analisis tanah dan tanaman dilakukan di Laboratorium Ilmu Tanah Jurusan Agroteknologi dan Laboratoium Pengelolaan Limbah Agroindustri Jurusan Teknologi Hasil Pertanian, Fakultas Pertanian, Universitas Lampung. Data yang diperoleh diuji homogenitasnya dengan uji Barlet dan adifitasnya dengan uji Tukey serta diolah dengan analisis ragam dan dilanjutkan dengan uji Beda Nyata Jujur (BNJ) pada taraf $5 \%$.

\section{HASIL DAN PEMBAHASAN}

Hasil analisis ragam menunjukkan bahwa pemupukan nitrogen berpengaruh nyata terhadap $\mathrm{pH}$ $\mathrm{KCl}$, tetapi pengaruh lainnya tidak nyata baik terhadap $\mathrm{pH} \mathrm{H}_{2} \mathrm{O}$ dan $\mathrm{pH} \mathrm{KCl}$ sebelum tanam. Pengaruh pemupukan nitrogen jangka panjang terhadap $\mathrm{pH} \mathrm{H} 2 \mathrm{O}$ dan $\mathrm{pH} \mathrm{KCl}$ sebelum tanam disajikan pada Tabel 1. Tabel tersebut menunjukkan bahwa peningkatan dosis pupuk $\mathrm{N}$ tidak secara nyata menurunkan $\mathrm{pH} \mathrm{H} 2 \mathrm{O}$, tetapi secara nyata menurunkan $\mathrm{pH} \mathrm{KCl}$. Sedangkan hasil analisis ragam setelah panen menunjukkan bahwa pemupukan nitrogen berpengaruh nyata, tetapi sistem olah tanah dan interaksinya tidak berpengaruh nyata terhadap $\mathrm{pH} \mathrm{H}_{2} \mathrm{O}$ dan $\mathrm{pH} \mathrm{KCl} \mathrm{setelah} \mathrm{panen.} \mathrm{Pengaruh}$ pemupukan nitrogen jangka panjang terhadap $\mathrm{pH}_{2} \mathrm{O}$ dan $\mathrm{pH} \mathrm{KCl}$ setelah panen juga disajikan pada Tabel 1 yang menunjukkan bahwa peningkatan dosis pupuk $\mathrm{N}$ secara nyata menurunkan $\mathrm{pH} \mathrm{H}_{2} \mathrm{O}$ dan $\mathrm{pH} \mathrm{KCl}$.

Pada C-organik tanah sebelum tanam, hasil analisis ragam menunjukkan bahwa sistem olah tanah, pemupukan nitrogen, dan interaksinya tidak berpengaruh nyata terhadap C-organik tanah pada kedalaman 0-20 $\mathrm{cm}$ sebelum tanam. Pada $\mathrm{N}$-total tanah sebelum tanam, hasil analisis ragam menunjukkan bahwa sistem olah tanah berpengaruh nyata, tetapi pemupukan nitrogen dan interaksinya tidak berpengaruh nyata terhadap $\mathrm{N}$-total tanah pada kedalaman $0-20 \mathrm{~cm}$ sebelum tanam. Pengaruh sistem olah tanah jangka panjang terhadap $\mathrm{N}$-total tanah sebelum tanam disajikan pada Tabel 2. Tabel tersebut menunjukkan bahwa sistem olah tanah secara nyata dapat meningkatkan $\mathrm{N}$-total tanah.

Pada bobot kering brangkasan, gabah, dan tanaman, hasil analisis ragam menunjukkan bahwa pemupukan nitrogen berpengaruh nyata, tetapi sistem olah tanah dan interaksinya tidak berpengaruh nyata terhadap bobot kering brangkasan, gabah, dan tanaman. Pengaruh pemupukan nitrogen jangka panjang terhadap

Tabel 1. Pengaruh pemupukan nitrogen jangka panjang terhadap $\mathrm{pH} \mathrm{H} 2 \mathrm{O}$ dan $\mathrm{pH} \mathrm{KCl}$ pada kedalaman $0-20 \mathrm{~cm}$ sebelum tanam.

\begin{tabular}{ccccc}
\hline \multirow{2}{*}{$\begin{array}{c}\text { Pupuk Nitrogen } \\
\left(\mathrm{kg} \mathrm{N} \mathrm{ha}^{-1}\right)\end{array}$} & \multicolumn{2}{c}{ Sebelum tanam } & \multicolumn{2}{c}{ Setelah panen } \\
\cline { 2 - 5 } & $\mathrm{pH} \mathrm{H} \mathrm{H}_{2} \mathrm{pH} \mathrm{KCl}$ & $\mathrm{pH} \mathrm{H} \mathrm{H}_{2}$ & $\mathrm{pH} \mathrm{KCl}$ \\
\hline 0 & $5,54 \mathrm{a}$ & $5,24 \mathrm{a}$ & $6,15 \mathrm{a}$ & $5,06 \mathrm{a}$ \\
50 & $5,46 \mathrm{a}$ & $5,24 \mathrm{a}$ & $6,11 \mathrm{a}$ & $5,06 \mathrm{a}$ \\
100 & $5,44 \mathrm{a}$ & $4,91 \mathrm{~b}$ & $5,94 \mathrm{~b}$ & $4,80 \mathrm{~b}$ \\
\hline BNJ 0,05 & 0,13 & 0,13 & 0,16 & 0,17 \\
\hline
\end{tabular}

Keterangan: Angka yang diikuti oleh huruf yang sama tidak berbeda nyata dengan uji BNJ pada taraf $5 \%$ 
Tabel 2. Pengaruh sistem olah tanah jangka panjang terhadap N-total tanah pada kedalaman 0-20 $\mathrm{cm}$ sebelum tanam.

\begin{tabular}{lc}
\hline \multicolumn{1}{c}{ Perlakuan } & $\begin{array}{c}\text { N-total tanah } \\
\left(\mathrm{g} \mathrm{N} \mathrm{kg}^{-1}\right)\end{array}$ \\
\hline Olah Tanah Intensif & $1,37 \mathrm{~b}$ \\
Olah Tanah Minimum & $1,49 \mathrm{ab}$ \\
Tanpa Olah Tanah & $1,53 \mathrm{a}$ \\
\hline \multicolumn{1}{c}{ BNJ 0,05} & 0,16
\end{tabular}

Keterangan: Angka yang diikuti oleh huruf yang sama tidak berbeda nyata dengan uji BNJ pada taraf 5\%

bobot kering brangkasan, gabah, dan tanaman disajikan pada Tabel 3. Tabel tersebut menunjukkan bahwa peningkatan dosis pupuk $\mathrm{N}$ secara nyata dapat meningkatkan bobot kering brangkasan, gabah, dan tanaman.

Pada serapan C-organik brangkasan, gabah, dan tanaman, hasil analisis ragam menunjukkan bahwa pemupukan nitrogen berpengaruh nyata, tetapi sistem olah tanah dan interaksinya tidak berpengaruh nyata terhadap serapan C-organik brangkasan, gabah, dan tanaman. Pengaruh pemupukan nitrogen jangka panjang terhadap serapan C-organik brangkasan, gabah, dan tanaman disajikan pada Tabel 3. Tabel tersebut menunjukkan bahwa peningkatan dosis pupuk $\mathrm{N}$ secara nyata dapat meningkatkan serapan $\mathrm{C}$-organik brangkasan, gabah, dan tanaman.

Pada serapan N-total brangkasan, gabah, dan tanaman, hasil analisis ragam menunjukkan bahwa pemupukan nitrogen berpengaruh nyata, tetapi sistem olah tanah tidak berpengaruh nyata terhadap serapan $\mathrm{N}$-total brangkasan, gabah, dan tanaman. Selain itu, interaksinya berpengaruh nyata hanya pada serapan $\mathrm{N}$ total brangkasan. Pengaruh pemupukan nitrogen jangka panjang terhadap serapan $\mathrm{N}$-total brangkasan, gabah, dan tanaman disajikan pada Tabel 3. Tabel tersebut menunjukkan bahwa peningkatan dosis pupuk $\mathrm{N}$ secara nyata dapat meningkatkan serapan $\mathrm{N}$-total brangkasan, gabah, dan tanaman.

Pengaruh interaksi sistem olah tanah dan pemupukan nitrogen jangka panjang terhadap serapan $\mathrm{N}$-total brangkasan disajikan pada Tabel 4. Tabel tersebut menunjukkan bahwa interaksi olah tanah minimum dan pemupukan nitrogen dengan dosis $100 \mathrm{~kg}$ $\mathrm{N} \mathrm{ha}^{-1}$ menunjukkan hasil tertinggi sedangkan interaksi olah tanah intensif dan pemupukan nitrogen dengan dosis $0 \mathrm{~kg} \mathrm{~N} \mathrm{ha}^{-1}$ menunjukkan hasil terendah.

Pada efisiensi serapan $\mathrm{N}$ tanaman, hasil analisis ragam menunjukkan bahwa sistem olah tanah, pemupukan nitrogen, dan interaksinya tidak berpengaruh nyata terhadap efisiensi serapan $\mathrm{N}$ tanaman. Rerata efisiensi serapan $\mathrm{N}$ tanaman padi gogo pada OTM mencapai $20,42 \%$, sedangkan TOT $22,15 \%$, dan OTI $27,26 \%$. Selain itu pada pemupukan nitrogen dengan dosis $50 \mathrm{~kg} \mathrm{~N}^{-1}$ mencapai $20,07 \%$ sedangkan dosis $100 \mathrm{~kg} \mathrm{~N} \mathrm{ha}^{-1}$ mencapai $26,49 \%$.

Pengaruh pemupukan nitrogen jangka panjang terhadap serapan $\mathrm{N}$-total brangkasan, gabah, dan tanaman disajikan pada Tabel 3. Tabel tersebut menunjukkan bahwa peningkatan dosis pupuk $\mathrm{N}$ secara nyata dapat meningkatkan serapan $\mathrm{N}$-total brangkasan, gabah, dan tanaman padi gogo. Hal ini terjadi karena peningkatan jumlah hara dalam tanah akan berdampak positif terhadap serapan hara tanaman.

Pernyataan tersebut didukung oleh Notohadiprawiro dkk. (2006), yang menyatakan bahwa pemupukan adalah proses pemberian bahan ke dalam tanah dengan tujuan memperbaiki, meningkatkan kesuburan, dan kandungan unsur hara tanah. Menurut Nyanjang (2003), bahwa pemupukan yang lengkap dan berimbang sangat mempengaruhi serapan hara tanaman padi karena dapat menambah dan mengembalikan unsur hara yang telah hilang baik tercuci maupun yang terbawa tanaman saat panen.

Tabel 3. Pengaruh pemupukan nitrogen jangka panjang terhadap bobot kering dan serapan C-organik pada brangkasan, gabah, dan tanaman padi gogo.

\begin{tabular}{ccccccccccc}
\hline $\begin{array}{c}\text { Pupuk } \\
\text { Nitrogen } \\
\left(\mathrm{kg} \mathrm{N} \mathrm{ha}^{-1}\right)\end{array}$ & \multicolumn{3}{c}{ Bobot kering $\left(\right.$ ton h $\left.\mathrm{h}^{-1}\right)$} & \multicolumn{3}{c}{ Serapan C-organik $\left(\right.$ ton C ha $\left.{ }^{-1}\right)$} & \multicolumn{3}{c}{ Serapan N-total $\left(\mathrm{kg} \mathrm{N} \mathrm{ha}^{-1}\right)$} \\
\cline { 2 - 11 } & Brangkasan & Gabah & Tanaman & Brangkasan & Gabah & Tanaman & Brangkasan & Gabah & Tanaman \\
\hline 0 & $2,19 \mathrm{~b}$ & $0,64 \mathrm{~b}$ & $2,86 \mathrm{c}$ & $0,79 \mathrm{~b}$ & $0,27 \mathrm{~b}$ & $1,08 \mathrm{c}$ & $9,92 \mathrm{c}$ & 6,82 & $\mathrm{~b}$ & $16,53 \mathrm{c}$ \\
50 & $3,76 \mathrm{a}$ & $0,84 \mathrm{~b}$ & $4,54 \mathrm{~b}$ & $1,44 \mathrm{a}$ & $0,35 \mathrm{~b}$ & $1,81 \mathrm{~b}$ & $18,32 \mathrm{~b}$ & $8,57 \mathrm{~b}$ & $27,03 \mathrm{~b}$ \\
100 & $4,58 \mathrm{a}$ & $1,37 \mathrm{a}$ & $5,92 \mathrm{a}$ & $1,77 \mathrm{a}$ & $0,58 \mathrm{a}$ & $2,36 \mathrm{a}$ & $25,50 \mathrm{a}$ & $17,09 \mathrm{a}$ & $42,95 \mathrm{a}$ \\
\hline BNJ 0.05 & 1,05 & 0,32 & 1,17 & 0,41 & 0,13 & 0,46 & 5,65 & 3,57 & 7,24 \\
\hline
\end{tabular}

Keterangan: Angka yang diikuti oleh huruf yang sama tidak berbeda nyata dengan uji BNJ pada taraf $5 \%$. 
Tabel 4. Pengaruh interaksi sistem olah tanah dan pemupukan nitrogen jangka panjang terhadap serapan $\mathrm{N}$-total brangkasan.

\begin{tabular}{|c|c|c|c|}
\hline \multirow{2}{*}{$\begin{array}{c}\text { Sistem } \\
\text { Olah Tanah }\end{array}$} & \multicolumn{3}{|c|}{ Pupuk Nitrogen $\left(\mathrm{kg} \mathrm{N} \mathrm{ha}^{-1}\right)$} \\
\hline & 0 & 50 & 100 \\
\hline & ............. & .......kg N he & .................. \\
\hline \multirow[t]{2}{*}{ Intensif } & $8,18 \mathrm{~b}$ & $16,16 \mathrm{ab}$ & $28,09 \mathrm{a}$ \\
\hline & $\mathrm{A}$ & $\mathrm{A}$ & $\mathrm{A}$ \\
\hline \multirow[t]{2}{*}{ Minimum } & $13,10 \mathrm{~b}$ & $16,48 \mathrm{ab}$ & $28,52 \mathrm{a}$ \\
\hline & $\mathrm{A}$ & A & $\mathrm{A}$ \\
\hline \multirow[t]{2}{*}{ Tanpa Olah } & $8,88 \mathrm{~b}$ & 22,75 a & $20,43 \mathrm{a}$ \\
\hline & $\mathrm{A}$ & A & A \\
\hline BNJ 0.05 & 13,31 & & \\
\hline
\end{tabular}

Hasil tersebut sejalan dengan pengaruh pemupukan nitrogen jangka panjang terhadap serapan C-organik brangkasan, gabah, dan tanaman (Tabel 3). Tabel tersebut menunjukkan bahwa peningkatan dosis pupuk $\mathrm{N}$ secara nyata dapat meningkatkan serapan $\mathrm{C}$ organik brangkasan, gabah, dan tanaman padi gogo. Hal ini terjadi karena pemberian pupuk nitrogen sebagai sumber energi yang dapat meningkatkan aktivitas mikroorganisme tanah, sehingga dekomposisi bahan organik dan mineralisasi unsur hara dapat berjalan dengan cepat dan unsur hara dapat diserap oleh tanaman. Hal ini sesuai dengan pendapat Hanafiah dkk. (2009), yang menyatakan bahwa kecepatan dekomposisi bahan organik oleh mikroba perombak tanah dipengaruhi ketersedian nitrogen, sebab kecepatan dekomposisi bahan organik sebanding dengan nitrogen yang ditambahkan ke dalam tanah. Selain itu bahan organik mampu meningkatkan daya serap dan daya simpan air sehingga hara tersedia yang berada di dalam larutan tanah dapat terangkut dan diserap oleh perakaran tanaman (Yuliarti, 2009).

Hal ini didukung dengan pengaruh pemupukan nitrogen jangka panjang terhadap bobot kering brangkasan, gabah, dan tanaman (Tabel 3). Tabel tersebut menunjukkan bahwa peningkatan dosis pupuk $\mathrm{N}$ secara nyata dapat meningkatkan bobot kering brangkasan, gabah, dan tanaman padi gogo. Musfal (2010), menyatakan bahwa bobot kering tanaman mencerminkan pertumbuhan tanaman dan banyaknya unsur hara yang terserap per satuan bobot biomassa yang dihasilkan. Semakin berat bobot kering tanaman yang dihasilkan, pertumbuhan tanaman semakin baik dan unsur hara yang terserap tanaman semakin banyak. Selain itu pengaruh interaksi sistem olah tanah dan pemupukan nitrogen jangka panjang terhadap serapan $\mathrm{N}$-total brangkasan (Tabel 4) menunjukkan bahwa interaksi olah tanah minimum dan pemupukan nitrogen

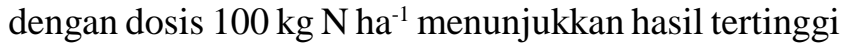
sedangkan interaksi olah tanah intensif dan pemupukan nitrogen dengan dosis $0 \mathrm{~kg} \mathrm{~N}^{-1}$ menunjukkan hasil terendah.

Menurut Alavan (2015), hal ini diduga karena pada olah tanah minimum terdapat bahan organik yang lebih optimal sehingga dapat menghindari kehilangan unsur hara akibat penguapan dan erosi serta pemanfaatan air lebih efisien bagi tanaman. Hal ini sesuai dengan pendapat Sutono dkk. (1996), yang menyatakan bahwa bahan organik sangat berperan dalam mencegah kehilangan unsur hara akibat penguapan dan erosi sehingga serapan hara dapat meningkat.

Walaupun pupuk urea dapat meningkatkan bobot kering serta serapan hara pada brangkasan, gabah, dan tanaman padi gogo (Tabel 3 dan 4), akan tetapi pupuk urea juga memiliki kecenderungan untuk menurunkan nilai $\mathrm{pH}$ tanah atau mengasamkan tanah. Hal ini sesuai dengan pengaruh pemupukan nitrogen jangka panjang terhadap $\mathrm{pH} \mathrm{KCl}$ sebelum tanam maupun $\mathrm{pH} \mathrm{H}_{2} \mathrm{O}$ dan pH KCl setelah panen (Tabel 1). Tabel tersebut menunjukkan bahwa peningkatan dosis pupuk $\mathrm{N}$ secara nyata menurunkan $\mathrm{pH} \mathrm{H}_{2} \mathrm{O}$ dan $\mathrm{pH} \mathrm{KCl}$.

Foth (1994), mengemukakan bahwa pupuk yang mengandung nitrogen dalam bentuk amonia atau dalam bentuk lainnya dapat berubah menjadi nitrat yang 
berakibat pada penurunan $\mathrm{pH}$ tanah. Menurut Kultural dan Schwab (2005), sumber utama keasaman dari pupuk urea dihasilkan oleh konversi ammonium $\left(\mathrm{NH}_{4}^{+}\right)$menjadi nitrat $\left(\mathrm{NO}_{3}^{-}\right)$akan melepaskan $\mathrm{H}^{+}$di dalam tanah. Pupuk urea tidak mengandung $\mathrm{NH}_{4}{ }^{+}$tetapi setelah diaplikasikan ke dalam tanah akan secara cepat dihidrolisis oleh adanya enzim urease menghasilkan $\mathrm{NH}_{4}^{+}$dan $\mathrm{HCO}_{3}^{-}$(Winarso, 2005).

Hasil analisis ragam menunjukkan bahwa sistem olah tanah, pemupukan nitrogen, dan interaksinya tidak berpengaruh nyata terhadap efisiensi serapan N. Rerata efisiensi serapan $\mathrm{N}$ tanaman padi gogo pada OTM mencapai $20,42 \%$, sedangkan TOT $22,15 \%$, dan OTI $27,26 \%$. Selain itu pada pemupukan nitrogen dengan dosis $50 \mathrm{~kg} \mathrm{~N}^{-1}$ mencapai $20,07 \%$ sedangkan dosis $100 \mathrm{~kg} \mathrm{~N} \mathrm{ha}^{-1}$ mencapai $26,49 \%$.

Hal ini terjadi karena pemupukan $\mathrm{N}$ yang diberikan pada olah tanah konservasi diimobilisasi oleh mikroba untuk mendekomposisi bahan organik, sedangkan pada olah tanah intensif yang tidak ditambahkan bahan organik tidak ada sumbangan kapasitas tukar kation dan sulit diharapkan terjadi imobilisasi N-pupuk dengan intensitas yang berarti. Selain itu, pemupukan $\mathrm{N}$ pada olah tanah intensif sebagian besar hilang dari zona perakaran tanarnan, misalnya karena erosi, penguapan, pencucian, dan lain-lain (Idawati dan Haryanto, 2001).

Pernyataan tersebut didukung dengan pengaruh sistem olah tanah jangka panjang terhadap N-total tanah sebelum tanam yang disajikan pada Tabel 2 yang menunjukkan bahwa sistem olah tanah secara nyata dapat meningkatkan $\mathrm{N}$-total tanah. N-total tanah pada tanpa olah tanah nyata lebih tinggi daripada olah tanah intensif, sedangkan olah tanah minimum tidak berbeda nyata dengan tanpa olah tanah dan olah tanah intensif.

Selain itu pernyataan tersebut juga diduga terjadi karena bahan organik yang terdapat pada sistem olah tanah minimum dan tanpa olah tanah terlalu sedikit yaitu hanya mencapai 6 - 8 ton ha ${ }^{-1}$ sehingga belum mampu untuk meningkatkan efisiensi serapan nitrogen (Ardiansyah, 2014). Hal ini didukung dengan hasil analisis ragam yang menunjukkan bahwa sistem olah tanah, pemupukan nitrogen, dan interaksinya tidak berpengaruh nyata terhadap $\mathrm{C}$-organik tanah pada kedalaman 0-20 cm sebelum tanam. Selain itu kadar C-organik tanah, berdasarkan kriteria penilaian hasil analisis tanah tergolong rendah yakni 1-2\% (Sulaeman dkk., 2005).

Menurut Abrol dkk. (2007), salah satu cara meningkatkan efisiensi penggunaan hara $\mathrm{N}$ yaitu dengan penggunaan bahan organik yang optimum. Ma dkk. (1999), juga menyatakan bahwa proses mineralisasi akibat penambahan bahan organik akan meningkatkan ketersedian $\mathrm{N}$, meningkatkan efisiensi penggunaan hara $\mathrm{N}$, serta mengurangi hilangnya $\mathrm{N}$ dari tanah.

\section{KESIMPULAN}

Berdasarkan hasil penelitian, maka diperoleh kesimpulan bahwa efisiensi serapan nitrogen antara sistem olah tanah OTM, TOT, dan OTI tidak berbeda nyata, dengan rerata mencapai $20,42 \%, 22,15 \%$, dan $27,26 \%$. Efisiensi serapan nitrogen antara pemupukan nitrogen dosis $50 \mathrm{~kg} \mathrm{~N}^{-1}$ dan $100 \mathrm{~kg} \mathrm{~N}^{-1} \mathrm{ha}^{-1}$ tidak berbeda nyata, dengan rerata mencapai $20,07 \%$ dan $26,49 \%$ serta tidak terdapat pengaruh interaksi antara sistem olah tanah dan pemupukan nitrogen jangka panjang terhadap efisiensi serapan nitrogen.

\section{DAFTAR PUSTAKA}

Abdurachman, A., A. Dariah, dan A. Rachman. 1998. Peranan pengolahan tanah dalam meningkatkan kesuburan (fisika, kimia, dan biologi) tanah. Prosiding Seminar Nasional VI Budidaya Olah Tanah Konservasi. Padang, 24 - 25 Maret 1998. 14 - $25 \mathrm{hlm}$.

Abrol, Y.P., S.R. Catterje, P.A. Kumar, V. Jain. 2007. Improvement in Nitrogen use Efficiency: Physiological and Molecular Approacheses. Tersedia: Http://www. ias.ac.m// aurrsci/may25/ articles.26.htm, [2 Agustus 2015].

Alavan, A. 2015. Pengaruh pemupukan terhadap pertumbuhan beberapa varietas padi gogo (Oryza sativa L.). J. Floratek 10: 61 - 68.

Ardiansyah, R. 2014. Pengaruh Sistem Olah Tanah dan Pemupukan Nitrogen Jangka Panjang terhadap Struktur Tanah, Bobot Isi, Ruang Pori Total, dan Kekerasan Tanah pada Pertanaman Kacang Hijau (Vigna radiata L.). Skripsi. Universitas Lampung. Bandar Lampung. $56 \mathrm{hlm}$.

Brady, N.C. dan R.R. Weil. 2008. The Nature and Properties of Soil. Person Education International, New Jersey. 965 p.

Foth, H. D. 1994. Dasar - Dasar Ilmu Tanah. Erlangga. Jakarta. $373 \mathrm{hlm}$.

Hanafiah, A.S., T. Sabrina, dan H. Guchi. 2009. Biologi dan Ekologi Tanah. Universitas Sumatera Utara Press. Medan. 146 hlm.

Idawati dan Haryanto. 2001. Kombinasi bahan organik dan pupuk $\mathrm{N}$ inorganik untuk meningkatkan hasil 
dan serapan N padi gogo. Risalah Petemuan Ilmiah Penelilian dan Pengembangan Aplikasi Isolop dan Radiasi. Puslitbang Teknologi Isotop dan Radiasi, BATAN. Jakarta. 287 - 293 hlm.

Kurtural, S. K. dan G. Schwab. 2005. Acidification of Vineyard Soils by Nitrogen Fertilizers. Cooperative Extension Service. Horticulture Department - University of Kentucky. 173 - 199 hlm.

Ma, B.L., L.M. Dwyer, dan E.G. Gregorich. 1999. Soil nitrogen amendment effects on seasonal nitrogen mineralization and nitrogen cycling in maize production. Agron J. 91: 1003 - 1009.

Musfal. 2010. Potensi cendawan mikoriza arbuskula untuk meningkatkan hasil tanaman jagung. J.Litbang Pertanian. 29(4): 154 - 158.

Notohadiprawiro, T., S. Soekodarmodjo, E. Sukana. 2006. Peranan Pupuk dalam Pembanguna Pertanian. Tersedia: Http://soil.faperta.ugm.ac.id, [1 Agustus 2015].

Nyanjang, R., A.A. Salim, dan Y. Rahmiati. 2003. Penggunaan pupuk majemuk NPK 25-7-7 terhadap peningkatan produksi mutu pada tanaman menghasilkan di tanah Andisols, PT. Perkebunan Nusantara XII. Prosiding. 133 - 145 hlm.
Sulaeman, Suparto, dan Eviati. 2005. Petunjuk Teknis: Analisis Kimia Tanah, Tanaman, Air, dan Pupuk. Balai Penelitian Tanah. Bogor. 136 hlm.

Sutono, S., A. Abdurachman, dan I. Juarsah. 1996. Perbaikan tanah Podsolik Merah Kuning (Haplorthox) menggunakan bahan organik dan anorganik: suatu percobaan rumah kaca. Prosiding Pertemuan Pembahasan dan Komunikasi Hasil Penelitian Tanah dan Agroklimat. Puslittanak. 23 - 27 hlm.

Sutedjo, M.M. dan A.G. Kartasapoetra. 2002. Pupuk dan Cara Pemupukan. Rineka Cipta. Jakarta. $177 \mathrm{hlm}$.

Toha, H.M. 2005. Padi Gogo dan Pola Pengembangannya. Departemen Pertanian. Jakarta. $48 \mathrm{hlm}$.

Utomo, M. 2012. Tanpa Olah Tanah: Teknologi Pengelolaan Pertanian Lahan Kering. Lembaga Penelitian Universitas Lampung. Bandar Lampung. $110 \mathrm{hlm}$.

Winarso, S. 2005. Kesuburan Tanah, Dasar Kesehatan dan Kualitas Tanah. Gava Media. Yogyakarta. $98 \mathrm{hlm}$.

Yuliarti, N. 2009. 1001 Cara Menghasilkan Pupuk Organik. Andi. Yogyakarta. $76 \mathrm{hlm}$. 